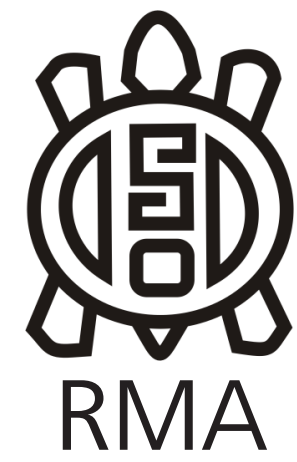

Dossier

\title{
Cazadores-recolectores y construcción de nicho en el bosque patagónico: el caso del valle del río Pico (Centro-Oeste del Chubut)
}

\author{
Hunter-gatherers and niche construction in the Patagonian forest: the \\ case of the Pico river valley (Central-Western Chubut) \\ Vivian Scheinsohn*, Sabrina Leonardt**, \\ Florencia Rizzo** y Mercedes G. Fernández**
}

\begin{abstract}
* CONICET, Instituto Nacional de Antropología y Pensamiento Latinoamericano. Facultad de Filosofía y Letras (UBA), Argentina. E-mail: vscheinsohn@yahoo.com

** CONICET, Instituto Nacional de Antropología y Pensamiento Latinoamericano, Argentina. E-mail: sabrinaleonardt@yahoo.com.ar; florencia_rizzo@hotmail.com; fernandez_mercedesgrisel@hotmail.com
\end{abstract}

\begin{abstract}
Resumen
Este trabajo se propone presentar una síntesis de las investigaciones arqueológicas desarrolladas en el sector boscosolecotonal del valle del río Pico (Chubut, Argentina) y una agenda de trabajo enmarcada en la Teoría de Construcción de Nicho. Para ello, se analizan en primer lugar algunos de los factores que podrían estar incidiendo en el proceso de construcción de nicho de los cazadores-recolectores en este ambiente para el Holoceno tardío y las expectativas que de ellos se desprenden, para luego caracterizar el área ambiental y paleoambientalmente. Se presentan los resultados de las excavaciones y de las distintas líneas de evidencia arqueológicas analizadas y se discuten estos resultados en función de las expectativas planteadas. A partir de esta discusión se sugiere que el bosque del valle del Pico formaría parte de los circuitos de movilidad exploratorios realizados por poblaciones asentadas en lugares y colonizados/ocupados previamente, estando la construcción de nicho en un estadio inicial. Para finalizar, se establece una agenda de trabajo para continuar esta discusión.
\end{abstract}

Palabras clave: Construcción de nicho; Valle del río Pico; Patagonia; Bosque/ecotono; Cazadores-recolectores.

\begin{abstract}
This paper is aimed to present a synthesis of the archaeological investigations carried out in the forested I ecotonal sector of the Pico river valley (Chubut, Argentina) and a work agenda framed in Niche Construction Theory. In order to do so we first analyze some of the factors that could be influencing the hunter-gatherer niche-construction process in this environment, for the Late Holocene and the expectations that arise from them, and then we characterize the area environmental and paleoenvironmentally. The results of the excavations and of the different lines of archaeological evidence analyzed are presented and these results are discussed according to the expectations raised. Based on this discussion, it is suggested that the forest of the Pico valley would be part of the exploratory mobility circuits carried out by populations settled in places already colonized loccupied, with the construction of the niche setted at an initial stage. Finally, a work agenda is established to continue this discussion.
\end{abstract}

Key words: Niche construction; Pico river valley; Patagonia; Forest/ecotone; Hunters-gatherers.

\section{Introducción}

Cuando los organismos modifican y eligen componentes de su ambiente local, se dice que están construyendo su nicho (Odling-Smee et al., 2003). La Teoría de Construcción de Nicho (TCN, en adelante) se originó como una rama de la biología evolutiva que enfatiza la capacidad de los organismos de modificar su ambiente $y$, por ende, influenciar la evolución propia y la de otras especies (Odling-Smee et al., 2003). Fue introducida por Richard Lewontin (1982) creciendo multidisciplinariamente en las últimas décadas (Odling-Smee, 1988; Laland et al., 2000; Kendal et al., 2011 entre otros). Su aporte consiste en cambiar la dinámica del proceso evolutivo, ya que los organismos no solo se adaptan a su ambiente sino que también lo construyen.

Cuando trasladamos esta perspectiva a nuestra especie su pertinencia es aún mayor: si todo organismo modifica su ambiente, los seres humanos podemos hacerlo de una manera extensiva, contando con la cultura como herramienta principal. Bajo una importante variedad 
de terminologías (Rowley-Conwy y Layton, 2011), este concepto fue discutido por antropólogos y arqueólogos. Por ejemplo, Boyd y Richerson (1985) hablan de ambiente transmitido (transmitted environment) como aquel en el que las modificaciones ambientales hechas por una generación constriñen las decisiones o el aprendizaje de la siguiente. Si bien no ha sido una perspectiva muy frecuentada en la arqueología argentina se registran varios trabajos enmarcados en esta perspectiva (Belardi et al., 2016; Martínez y Mackie, 2003; Muscio, 2009; Rivero y Medina, 2016 entre otros).

La construcción de nicho afecta tanto a la dinámica evolutiva genética como a la cultural y también a la coevolución entre ambas, por lo que la TCN reconoce que la cultura es parte crucial de nuestra herencia ecológica y que se transmite a través de la modificación de ese ambiente. Si bien la cultura permite una modificación del ambiente, esto no quiere decir que nos permita separarnos del mismo: los humanos modificamos pero también realizamos una serie de selecciones a partir de lo que nos ofrece un determinado ambiente. Por ello creemos que una buena entrada a la construcción de nicho, en el caso de los cazadores-recolectores, debe pasar por las circunstancias ambientales en las que se da. Así, en lo que sigue presentaremos la caracterización ambiental del valle del río Pico, en donde se ubica nuestra investigación y discutiremos los recursos que puede ofrecer.

\section{El valle del río Pico: caracterización ambiental y paleoambiental}

El río Pico se ubica entre la Cordillera de los Andes y la Precordillera, en el Centro-Oeste de la provincia del Chubut. Su cuenca desagota en el Océano Pacífico y cubre, en el sector argentino, una superficie de aproximadamente $2.050 \mathrm{~km}^{2}$ (AA.VV., 2020), atravesando distintos biomas, desde el bosque situado al Oeste hasta el ecotono bosque-estepa y la estepa hacia al Este. El clima es templado frío, con precipitaciones anuales en el sector cordillerano que oscilan entre 800 y 1.600 mm, lo cual favorece el desarrollo de un bosque caducifolio caracterizado por distintas especies de Nothofagus. Como el valle del Pico posee una baja altitud relativa que permite un fácil acceso y circulación entre la meseta y los Andes, e incluso hasta la costa pacífica (Matteucci et al., 2011), presenta una situación ideal para evaluar el papel de la estepa y el bosque en las estrategias de uso del espacio de los cazadores-recolectores.

En cuanto a la información paleoambiental, la fuente más cercana corresponde a los testigos sedimentarios de lago Los Niños y laguna La Pava (Iglesias et al., 2016; ver ubicación en Figura 1), situados en el ecotono bosque-estepa actual. A partir del análisis litológico y de los registros de polen y carbón, los autores sostienen que entre 14.300 y 11.500 años cal AP se documentan los primeros momentos del establecimiento de bosque abierto en lago Los Niños y con posterioridad a esa fecha el desarrollo de un ambiente más cerrado de bosque de Nothofagus, en correspondencia con un incremento en los niveles de humedad. Durante el Holoceno medio (entre 5800 y 3000 cal AP), si bien no se observan importantes cambios en la composición de la vegetación, se registra un incremento en la frecuencia de incendios en ambas cuencas, lo que los autores asocian a un aumento en la variabilidad climática interanual. Por último, para el lapso

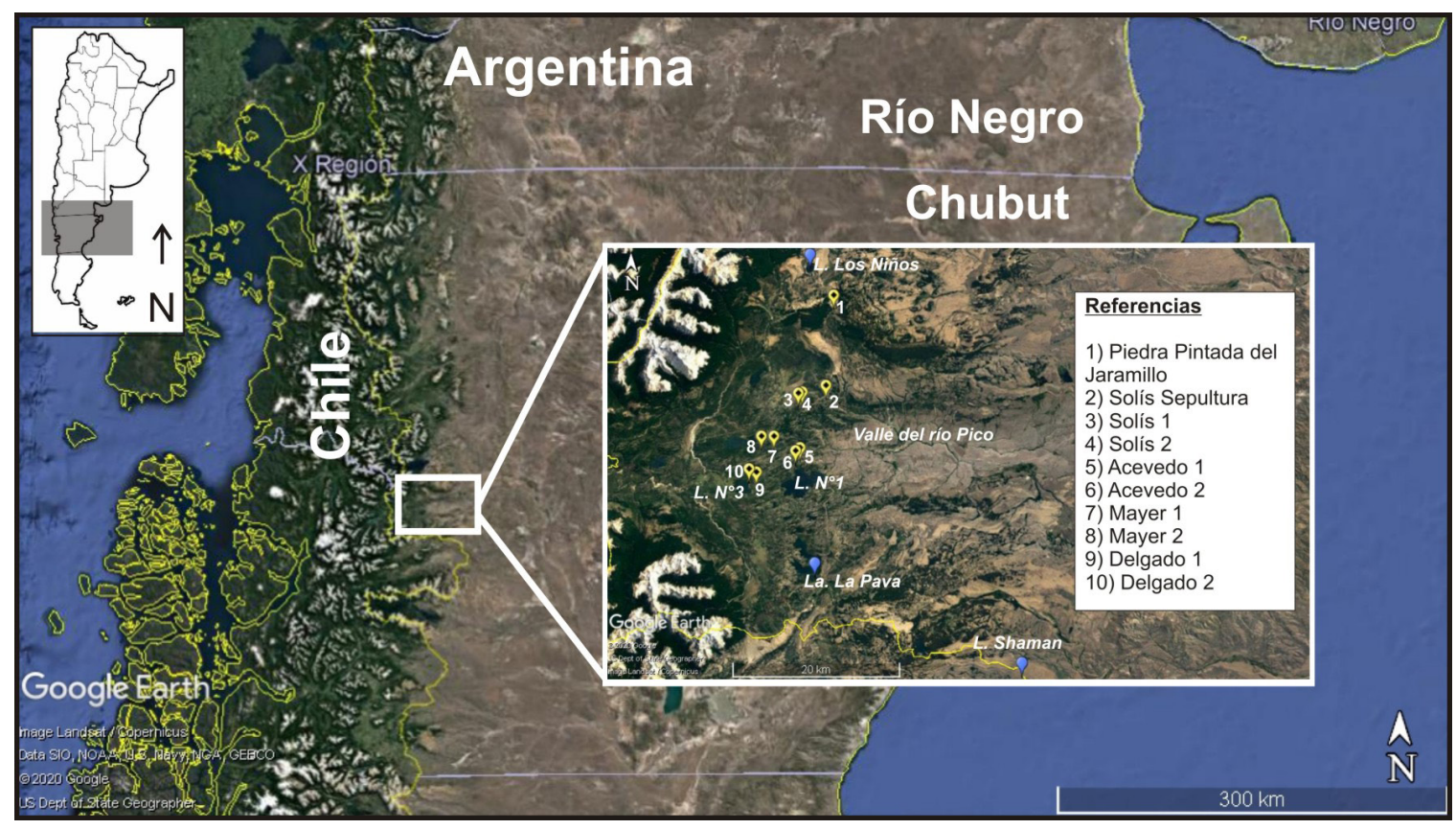

Figura 1. Ubicación del valle del río Pico y de los sitios arqueológicos allí registrados.

Figure 1. Location of the Pico river valley and the archaeological sites registered there. 
comprendido por los últimos 3000 años cal AP ambas cuencas están dominadas por bosque de Nothofagus, favorecido por condiciones de mayor humedad efectiva, aunque con un aumento en la frecuencia y magnitud de los episodios de incendios que los autores atribuyen a una "greater climate variability with the strengthening of ENSO and/or to more anthropogenic burning associated with the increase in human populations" (Iglesias et al., 2016:204). Como este aumento ocurre a lo largo de un gradiente de humedad que va del Archipiélago de Chonos al ecotono bosque-estepa "(...) increases in interanual or interdecadal variability seem to be the primary explanation" (Iglesias et al., 2016:204).

Los análisis realizados sobre el registro sedimentario del lago Shaman (Figura 1), ubicado en el cercano valle del río Cisnes (de Porras et al., 2012, Méndez et al., 2016), muestran una secuencia similar, marcada por el establecimiento de un ambiente ecotonal con posterioridad a 11.000 cal AP que se mantiene, con variaciones, durante todo el Holoceno temprano, asociado a una baja a moderada frecuencia de incendios. Para el Holoceno medio se registra el máximo desarrollo de bosque de Nothofagus y un incremento de incendios, en correspondencia con una alta variabilidad climática. Finalmente, para los últimos 3000 años cal AP la frecuencia e intensidad de incendios se potencia y se registra una retracción del bosque y el establecimiento del ecotono bosque-estepa moderno como consecuencia de los cambios inducidos por el fuego (de Porras et al., 2012). En el caso del flanco Este de los Andes del CentroOeste patagónico, Méndez et al. (2016) sostienen que, aunque el clima es el principal control de la ocurrencia de fuegos en escalas amplias, dada la correspondencia entre ocupaciones humanas e incendios "both the unintentional spread of human camp fires and deliberate burning can be considered as potential contributors to wild fires" (Méndez et al., 2016:15).

Así, sobre la base de estos trabajos, puede sostenerse que el área en donde están localizados los sitios del valle del río Pico (Figura 1), si bien con fluctuaciones, habría estado dominada por un ambiente boscoso durante la mayor parte del Holoceno. Hacia los 3000 años cal. AP se establecen las condiciones actuales, marcadas por una alta variabilidad climática y por un incremento en la frecuencia de los incendios.

\section{Recursos disponibles en el bosque patagónico entre los $41^{\circ}-46^{\circ}$ lat. Sur y expectativas arqueológicas}

\section{Vegetales}

Entre los recursos que ofrecen los bosques andinopatagónicos destacan los vegetales, cuyo aprovechamiento es conocido a través de cronistas y viajeros (Musters, [1871] 2007 entre otros), así como también a partir de trabajos etnobotánicos (Ladio et al., 2007; Smith, 1998; Toledo y Kutschker, 2012 entre otros). Éstos dan cuenta de que el conocimiento sobre el uso de plantas implica un complejo proceso de aprendizaje y transmisión intergeneracional. Ese es el caso de plantas ricas en nutrientes pero que necesitan un procesamiento previo a su consumo para mejorar su palatabilidad o para desintoxicarlas (Borrero et al., 2019).

Rapoport y Ladio (1999: Cuadro 2) fijaron una lista de 60 especies de plantas nativas potencialmente comestibles para los bosques cordilleranos del Sur de Chile y Argentina. Como los trabajos arqueobotánicos son menos frecuentes en el bosque (Arrigoni, 2002; Caruso Fermé, 2013) que en la estepa (Ciampagna y Capparelli, 2012; Marconetto, 2002; Pérez de Micou, 1991 entre otros) determinar cuáles fueron efectivamente aprovechadas en el pasado es complejo. Esta escasez de trabajos arqueobotánicos en el bosque puede deberse a los problemas de preservación que presentan esos restos en este bioma, pero también a que muchas veces los arqueólogos nos concentramos en el análisis de restos carbonizados o artefactuales, antes que en los comestibles o medicinales. La necesidad de recurrir al bosque para la obtención de recursos vegetales específicos se manifiesta, por ejemplo, en el registro de la caña colihue (Chusquea culeou) en sitios arqueológicos ubicados en la estepa (Gradin, 1978; Pérez de Micou, 2002 entre otros) y, a través de fuentes históricas, en el uso de postes para la instalación de toldos (Nacuzzi y Pérez de Micou, 1983-1985).

Al contrastar con la evidencia arqueobotánica de los alrededores del Pico, vemos que en los sitios El Chueco I y Baño Nuevo 1, ambos localizados en la estepa, Belmar, Méndez y Reyes (2017) encuentran que la mayor riqueza de semillas registrada corresponde al Holoceno tardío, pero sugieren que esto podría deberse tanto a la menor cantidad de sitios tempranos (y por ende menor riqueza) como a una mayor presencia de gente y densidad de sitios en momentos tardíos. En el Alero Las Quemas, ubicado en el bosque, encuentran un patrón similar (Belmar et al., 2017).

En cuanto al papel de los vegetales en la dieta, es necesario destacar que Binford (2001), a partir de una muestra global de 339 sociedades de cazadores-recolectores que representan diversas condiciones climáticas, geográficas, ecológicas y culturales, evaluó que, a estas latitudes, los vegetales aportarían hasta el 35\% de la dieta. Por ello, podríamos pensar que tal vez estos recursos hayan sido más importantes de lo que la evidencia arqueológica permite sostener hasta el momento.

Al mismo tiempo se ha argumentado que la ocupación recurrente de ciertos sitios por parte de los cazadoresrecolectores lleva a modificar el entorno, favoreciendo la presencia de especies que fueron aprovechadas y desechadas en ese mismo lugar. Se logra así, de manera no intencional, que en las cercanías de un sitio se desarrollen aquellas especies regularmente explotadas, 
dando lugar a huertos silvestres (wild orchads según Politis, 2007:145-153; ver también Gnecco, 2000 y Groß et al. 2019). No se han comprobado casos de este tipo para los bosques patagónicos, pero Belmar et al. (2017) argumentan que:

\section{"...it is possible to suggest that there were more deliberate provisioning strategies according to the use of the plant. It is also necessary to consider that some parts of plants may have been brought to the site accidentally, for example as part of other materials used for making artefacts" (Belmar et al., 2017:16).}

\section{Agua}

A diferencia de lo que sucede en la estepa, la presencia de numerosos cursos, lagos y lagunas en el bosque garantizan su constante disponibilidad, por lo que este ambiente podría constituirse en un refugio en los momentos de mayor aridez (Bellelli et al., 2000 entre otros). Las evidencias paleoambientales descriptas anteriormente no muestran eventos marcados de aridez en el área, aunque existen evidencias de variaciones interanuales en el último tramo del Holoceno. Por ello, pensamos que la disponibilidad de agua no se habría visto mayormente afectada en el valle del Pico. Sin embargo, regionalmente, tanto Méndez et al. (2016) como Iglesias et al. (2016) destacan un aumento en los incendios forestales para este momento que podrían estar relacionados con una menor humedad, al menos a escala local.

\section{Fauna}

En lo que respecta a las presas potenciales, aquellas de mayor rendimiento son mamíferos de porte mediano a pequeño y de hábitos solitarios, como el huemul (Hippocamelus bisulcus) o el pudú (Pudu puda), lo que plantea una caza por encuentro (Fernández y Carballido, 2015) y con un rinde que permite sustentar grupos pequeños y altamente móviles en el bosque (Bellelli et al., 2000; Fernández, 2010). El consumo de vertebrados pequeños, si bien ha sido registrado en sitios del área (por ejemplo, Fernández y Arrigoni, 2016; Méndez et al., 2006), no habría cambiado este panorama en vista de su bajo rinde. Regionalmente, el huemul domina los conjuntos faunísticos de los sitios ubicados en el interior del bosque, mientras que en el ecotono bosque-estepa la presa principal es el guanaco, debido a su mayor densidad poblacional (Fernández et al., 2016). Si bien son conocidos los problemas de preservación que tienen los huesos en los sitios de bosque (Arrigoni y Fernández, 2004), se puede plantear como expectativa para el Pico el aprovechamiento intensivo de escasos ungulados por sitio y el consumo de fauna menor.

\section{Navegabilidad y legibilidad ambiental}

El paisaje quebrado y la abundante vegetación imponen limitaciones a la circulación humana y dificultades en la navegación del territorio (Bellelli et al., 2008; Scheinsohn y Matteucci, 2004 entre otros). Una de esas dificultades se relaciona con un mayor riesgo de accidentes respecto de la estepa. Este factor fue uno de los considerados en la elaboración de un modelo de corredores de cazadoresrecolectores para el Noroeste de Patagonia (Scheinsohn y Matteucci, 2013), donde se propuso un corredor de bajo riesgo y otro de alto riesgo de accidentes. En vista de que los cazadores-recolectores contarían con medios limitados para tratar con el trauma, sostuvimos que evitarían los accidentes viajando a través de un territorio más seguro (Scheinsohn y Matteucci, 2013). En concordancia con esta expectativa, de los 22 sitios registrados por entonces 19 se situaban en el corredor de menor riesgo. Por otro lado, la legibilidad ambiental (sensu Golledge, 2003) en el bosque es compleja. Para otros sectores de Patagonia se ha propuesto que el arte rupestre ayudaría a esa legibilidad ambiental además de favorecer la navegabilidad terrestre (Scheinsohn, 2011), señalando un ambiente transmitido (sensu Boyd y Richerson, 1985 en Scheinsohn y Matteucci, 2013, ver también Lovis y Whallon, 2016; Scheinsohn, 2011).

Así, para el valle del Pico, la expectativa es encontrar sitios con arte rupestre que estén ubicados en corredores de bajo riesgo y que funcionen como hitos que facilitarían la navegación terrestre en el bosque. A esto se suma que los lagos y ríos pueden ofrecer posibilidades de navegación acuática (Carabias et al., 2010) ya que diversas fuentes informan sobre el uso de embarcaciones en los bosques cordilleranos del Norte de Patagonia (véase Fernández, 1997; Braicovich, 2007; Carabias et al., 2010 entre otros).

\section{Estrés patogénico}

A nivel global, los seres humanos experimentan el mayor nivel de estrés patogénico a los 0 grados de latitud y el menor en los polos (Binford, 2001; Cashdan, 2014; Low, 1990). En nuestro caso, consideramos que las diferencias ambientales registradas a la misma latitud justifican un tratamiento en términos relativos. Así, a igualdad de temperatura, siendo el bosque el sector que registra mayor humedad, supondrá un mayor estrés patogénico que la estepa'. A modo de ejemplo, consideraremos aquellos patógenos transmisibles por roedores e insectos (ambos señalados como principales fuentes de contaminación microbiana, Binford, 2001:430). La interpretación de la presencia arqueológica de los roedores en reparos rocosos estuvo orientada a su alternancia con las ocupaciones humanas, a la evaluación paleoambiental y al consumo de los mismos, pero poco se ha dicho sobre su convivencia. Creemos que se podría plantear una cohabitación en reparos rocosos con algunas especies ya que el asentamiento humano facilitaría su alimentación al modificar el entorno y arrojar desechos. En el caso del bosque andino-patagónico, la presencia de Oligoryzomys longicaudatus (ratón colilargo), que en la actualidad

\footnotetext{
1 La temperatura y humedad serían los reguladores del éxito reproductivo de los patógenos (véase Binford, 2001:440).
} 


\begin{tabular}{|c|c|c|c|c|c|c|c|}
\hline \multirow[b]{2}{*}{ Sitio } & \multirow[b]{2}{*}{$\begin{array}{l}\text { Procedencia } \\
\text { de la } \\
\text { evidencia }\end{array}$} & \multicolumn{6}{|c|}{ Tipo de registro material } \\
\hline & & $\begin{array}{c}\text { Manifestaciones } \\
\text { rupestres }\end{array}$ & \begin{tabular}{|c|} 
Restos \\
óseos \\
humanos \\
\end{tabular} & $\begin{array}{c}\text { Artefactos } \\
\text { líticos }\end{array}$ & $\begin{array}{c}\text { Restos } \\
\text { de } \\
\text { fauna }\end{array}$ & $\begin{array}{c}\text { Estructuras } \\
\text { de piedra }\end{array}$ & Canoamonóxila \\
\hline Acevedo 1 & $\begin{array}{c}\text { relevamiento } \\
\text { sistemático y } \\
\text { excavación }\end{array}$ & $x$ & $x$ & $x$ & $x$ & & \\
\hline Acevedo 2 & $\begin{array}{l}\text { colección } \\
\text { privada }\end{array}$ & & & $x$ & & & \\
\hline Solis 1 & $\begin{array}{c}\text { relevamiento } \\
\text { sistemático y } \\
\text { excavación }\end{array}$ & $x$ & & & & & \\
\hline Solis 2 & $\begin{array}{c}\text { relevamiento } \\
\text { sistemático }\end{array}$ & & & & & $x$ & \\
\hline $\begin{array}{c}\text { Solis } \\
\text { Sepultura }\end{array}$ & $\begin{array}{l}\text { colección } \\
\text { privada }\end{array}$ & & $x$ & & & & \\
\hline $\begin{array}{c}\text { Piedra } \\
\text { Pintada del } \\
\text { Jaramillo }\end{array}$ & $\begin{array}{c}\text { relevamiento } \\
\text { sistemático }\end{array}$ & $x$ & & & & & \\
\hline Mayer 1 & $\begin{array}{l}\text { colección } \\
\text { privada }\end{array}$ & & & $x$ & & & \\
\hline Mayer 2 & \begin{tabular}{|c|} 
relevamiento \\
sistemático
\end{tabular} & & & & & $x$ & \\
\hline Delgado 1 & $\begin{array}{l}\text { colección } \\
\text { privada }\end{array}$ & & & $x$ & & & \\
\hline Delgado 2 & $\begin{array}{c}\text { colección } \\
\text { CENPAT }\end{array}$ & & & & & & $x$ \\
\hline $\begin{array}{c}\text { Campamento } \\
\text { Río Pico }\end{array}$ & $\begin{array}{l}\text { colección } \\
\text { MCNLP }\end{array}$ & & $x$ & & & & \\
\hline
\end{tabular}

Tabla 1. Características generales del registro material recuperado en el valle del río Pico.

Table 1. General characteristics of the material record recovered in the Pico river valley.

es conocido por ser reservorio primario del Hantavirus ${ }^{2}$ (Polop et al., 2018), señala al menos un caso actual de una enfermedad propia de ese ambiente.Aunque este ratón fue registrado en sitios arqueológicos boscosos (p.ej. Risco de Azócar 1, Andrade y Fernández, 2017), se desconoce la antigüedad de la presencia de este virus y si pudo afectar a las poblaciones de cazadores-recolectores. Por lo tanto, es esperable que se hayan diseñado estrategias para lidiar con los roedores (p. ej. la movilidad, colocación de trampas, entre otras), cuya visibilidad arqueológica no es evidente.

En síntesis, los aspectos enumerados sugieren que el proceso de construcción de nicho pudo ser de largo plazo, discontinuo y heterogéneo en el espacio. En concordancia con el modelo de poblamiento planteado por Borrero (1994-1995), posiblemente las primeras estrategias habrían consistido en hacer incursiones acotadas en el bosque, en el marco de una etapa de exploración. Luego, esto podría haber llevado, por ejemplo, a una mayor permanencia humana en este ambiente, como plantean Fernández et al. $(2013,2019)$ y Fernández y Fernández (2020).

En lo que sigue presentaremos los resultados de nuestras investigaciones arqueológicas, para discutir las expectativas aquí planteadas y fijar una agenda de trabajo.

\section{Investigaciones arqueológicas en el valle del río Pico}

Las investigaciones realizadas en el valle del río Pico desde 2009 han permitido documentar diversas evidencias arqueológicas (Tabla 1). No obstante, la calidad de información que brinda cada una es dispar. Mientras que todos los sitios con manifestaciones rupestres fueron

\footnotetext{
2 Y cuyas características morfológicas coinciden con aquellas planteadas por Weissbrod et al. (2017), como seleccionadas para las especies de ratones comensales con los humanos.
}

relevados por nuestro equipo y en dos casos se realizaron excavaciones arqueológicas sistemáticas (Acevedo 1 y Solís 1, Figura 1), la mayor parte de los conjuntos líticos de sitios a cielo abierto proceden de colecciones privadas. Se trata de materiales que estaban enterrados y fueron recolectados en distintas circunstancias (ver abajo). En otro trabajo hemos planteado que el enterramiento es esperable en el bosque, donde predominan los procesos de sedimentación y generan como consecuencia problemas de visibilidad arqueológica (Rizzo et al., 2016). Asimismo, parte de los conjuntos de restos óseos humanos también proceden de colecciones (ver abajo: sitio Solís Sepultura, Figura 1 y Tabla 1 y Campamento Río Pico en Tabla 1).

En vista de estas diferencias de calidad, presentaremos primero en detalle las evidencias obtenidas en los sitios excavados por nuestro equipo para luego analizar en conjunto las distintas líneas de evidencia obtenidas en estos sitios y aquellas procedentes de colecciones privadas.

\section{Excavaciones}

Acevedo 1 es un alero de 40 m de extensión emplazado en una formación de rocas aborregadas de origen glaciario, en las cercanías del Lago $N^{\circ} 1$ (Figura 1). Se orienta hacia el Norte con un reparo de entre 2 y $4 \mathrm{~m}$ de profundidad, desde la pared hasta la línea de goteo (Rizzo, 2017; Scheinsohn et al., 2016 y Figura 2). Allí se contabilizaron un total de 37 motivos rupestres, predominantemente abstractos/geométricos (Tabla 2), todos pintados y en distintas tonalidades de rojo. No hay representaciones humanas ni animales.

Las pinturas poseen un importante estado de deterioro, debido tanto a la acción de procesos naturales como antrópicos. El primer caso se refleja en su distribución, ya que son discontinuas y se ubican desde el centro 

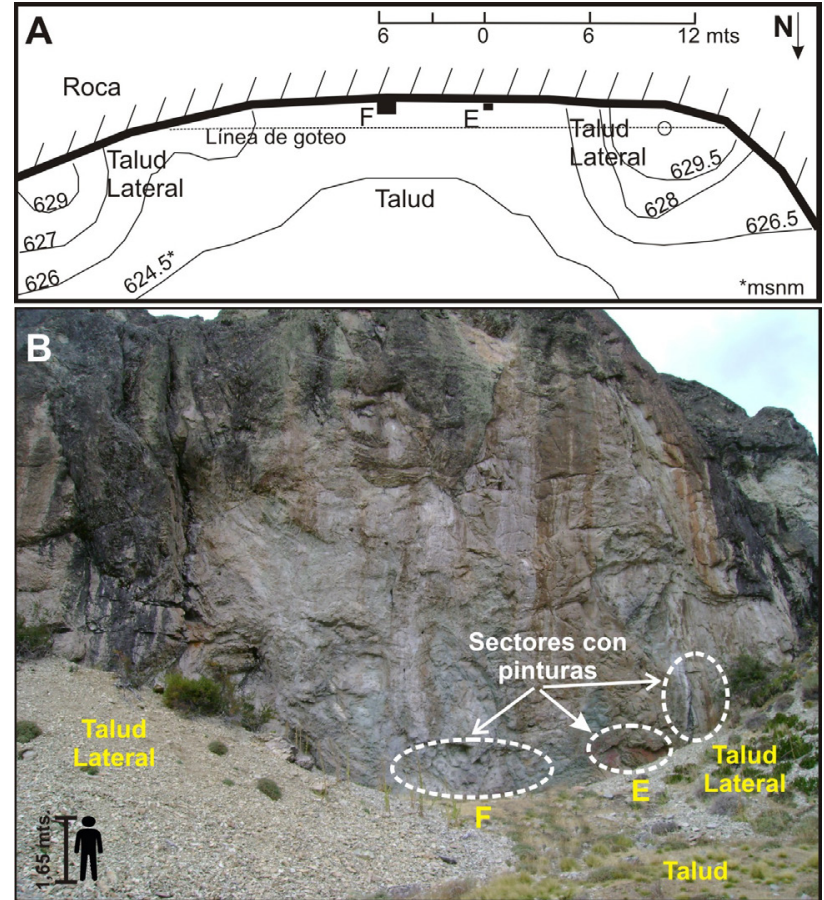

Figura 2. A) detalle en planta de las excavaciones del sitio Acevedo 1 y su entorno; B) vista frontal del alero Acevedo 1 y detalle de los sectores con pinturas.

Figure 2. A) Plan view of the excavations of the Acevedo 1 site and its surroundings; $B$ ) front view of Acevedo 1 and detail of the sectors with cave paintings.

del paredón hacia su extremo Oeste (Figura 2). En el sector central se observan cicatrices frescas que indican el desprendimiento de rocas, lo que podría implicar la destrucción de motivos que se hubieran pintado allí. La acción antrópica actual, por su parte, se evidencia en la presencia de piqueteo y rayado de motivos.

En este sitio se excavaron dos sectores separados entre sí por cinco metros, uno situado en el centro del paredón (cuadrícula F) y otro en el extremo Oeste (cuadrícula E, Figura 2), totalizando $3 \mathrm{~m}^{2}$. Se excavaron mediante niveles artificiales de $10 \mathrm{~cm}$, alcanzándose una profundidad de 70 $\mathrm{cm}$, donde se detectó la presencia de un paleosuelo con un material parental fluvioglaciario. La capa intermedia se compone de ese mismo paleosuelo mezclado con material de origen coluvial y volcánico, procedente de la ladera adyacente al sitio. La capa superior está compuesta por coluvio (propio de la ladera) y guano. Allí se identificaron grandes bloques que pudieron depositarse por desprendimientos, rodamiento o incluso haber sido movilizados por los humanos (Rizzo, 2017; Scheinsohn et al., 2016). Como se dijo, si bien es difícil recuperar restos óseos en sitios del bosque (Arrigoni y Fernández, 2004; Fernández y Rizzo, 2016 entre otros), el caso de Acevedo 1 destaca en tanto se recuperaron 56 restos óseos y dentales humanos (Rizzo, 2017) y 2.366 restos faunísticos (Fernández, 2018; Fernández, en prensa; Rizzo y Fernández, 2020; Scheinsohn et al., 2016).
Además, se recuperó un artefacto bifacial de sílice y 225 desechos de talla de módulo muy pequeño a pequeño, predominantemente de sílice y calcedonia. Si bien el análisis de la estructura de los recursos líticos del Pico aún está en curso, en vista del registro de nódulos de calcedonia y sílice en el valle del Genoa (ubicado a $80 \mathrm{~km}$ al Este) y basalto/andesita en el Pico, suponemos que las materias primas más utilizadas son de disponibilidad local. La obsidiana es escasa y de origen alóctono, aunque por el tamaño pequeño de los desechos no se pudo determinar la fuente de procedencia. El análisis detallado del material lítico (a cargo de un equipo coordinado por la Dra. Mariana Carballido Calatayud) está en curso. Podemos adelantar que los tamaños de los desechos sugieren el desarrollo de actividades de retalla o retoque. Aparte del material lítico, se registró una cuenta y dos fragmentos pequeños de valva de molusco indeterminado.

El conjunto arqueofaunístico se compone principalmente de vertebrados pequeños ( $98 \%$ del NISP), como roedores y paseriformes, y escasos vertebrados grandes como oveja (Ovis aries), guanaco (Lama guanicoe), zorro (Lycalopex sp.), Mammalia, Artiodactyla y Canidae (Fernández, en prensa; Scheinsohn al., 2016). Dentro de los vertebrados pequeños, se determinó la presencia de Microcavia australis, Ctenomys sp. y de las familias Cricetidae y Caviidae (Fernández, en prensa). Dada la baja identificabilidad de los mamíferos de mayor porte (debido a su alta fragmentación) y la escasez de restos óseos en otros sitios del área, se realizó un análisis de citocromo b mitocondrial que permitió obtener la primera determinación taxonómica de huemul en el Centro-Oeste del Chubut (Scheinsohn et al., 2016). Sin embargo, las modificaciones óseas relacionadas con la actividad humana son escasas: sobre dos huesos asignados a Mammalia se registraron un negativo de lascado, un punto de impacto y una huella de corte muy fina. Uno de ellos fue el analizado mediante citocromo $b$ aunque no se logró determinar la especie (Scheinsohn et al., 2016). En cuanto a las modificaciones naturales, los huesos muestran una elevada incidencia de la actividad tafonómica de zorros y aves rapaces lo que sugiere que la mayor parte de esta muestra no está asociada a la actividad humana (Fernández, en prensa).

Los restos óseos humanos se presentaron con un importante nivel de mezcla y dispersión por lo que no pudo determinarse la presencia de estructuras de entierro ni establecerse su asociación directa con los restantes materiales arqueológicos recuperados. Estos restos corresponden, al menos, a dos individuos: un juvenil y un adulto, ambos de sexo indeterminado, datados en 1540 \pm 49 AP (AA98674, óseo, calibrado con dos sigmas en 460 cal A.D. - 645 cal A.D. ${ }^{3}$, Scheinsohn et al., 2016) y $1589 \pm 38$ AP (AA90944, óseo, calibrado con dos sigmas en 419 cal A.D.- 594 cal A.D., Scheinsohn et al., 2016),

\footnotetext{
3 Calibrado con CALIB RADIOCARBON CALIBRATION PROGRAM* Calib- Rev 7.0.4. Copyright 1986-2014. Stuiver y Reimer (1993).
} 


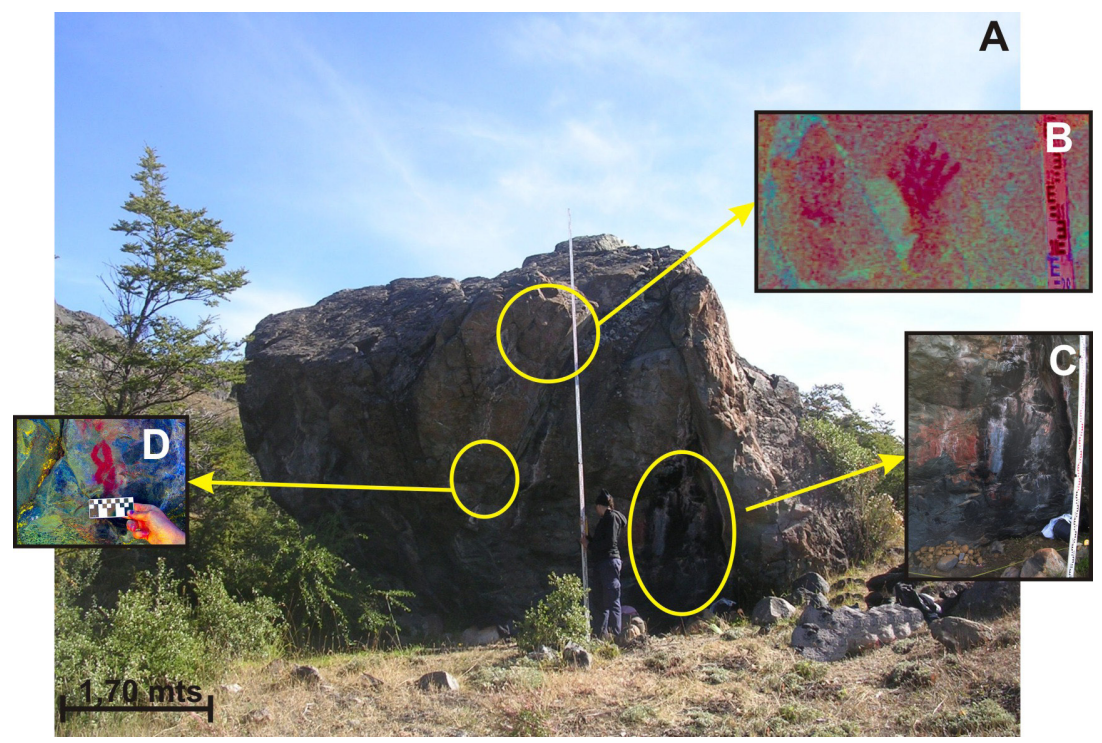

Figura 3. A) vista general del sitio Solís 1; B) detalle de las manos pintadas en rojo (retocado con DStretch); C) detalle del hollín adherido a la roca; D) motivo en "B invertida" (retocado con DStretch).

Figure 3. A) general view of the Solis 1 site; $B)$ detail of the hands painted in red (retouched with DStretch); C) detail of the soot adhered to the rock; D) "B inverted" motif (retouched with DStretch).

respectivamente. Para esta última muestra se obtuvieron datos isotópicos de $\delta C 13=-20,2$ y $\delta N 15=9,8$. El análisis tafonómico permitió sugerir que si bien el conjunto tuvo un rápido sepultamiento luego de su depositación (dada la ausencia de evidencias de meteorización), presenta un alto grado de alteraciones debido, principalmente, a la acción antrópica moderna (Rizzo, 2017; Rizzo y Fernández, 2020; Scheinsohn et al., 2016). La comparación de los restos óseos humanos y faunísticos determinó que ambos conjuntos presentan trayectorias tafonómicas diferentes dado que los restos humanos ingresaron al sitio en el contexto de actividades mortuorias (Rizzo, 2017) mientras que el conjunto faunístico es, en su mayoría (se registraron dos restos que presentan huellas antrópicas), resultado de la actividad de carnívoros y rapaces (Rizzo y Fernández, 2020). La compleja historia tafonómica de este sitio se manifiesta también en la mezcla de materiales dada por la presencia de huesos de oveja encontrados en el mismo nivel que los restos óseos humanos datados en ca. 1540 años AP (Rizzo y Fernández, 2020).

El otro sitio excavado es Solís 1 (Figura 1 y Figura 3a), un bloque errático ubicado a $30 \mathrm{~m}$ de un camino vecinal moderno y que proporciona un pequeño reparo que es actualmente utilizado por los trabajadores rurales (se registraron fogones recientes). Además, hasta mediados del siglo XX, el lugar fue usado como "dobladero" de las carretas con bueyes, del viejo camino que conectaba con Aldea Las Pampas. Sobre la cara Este del bloque se identificaron 11 motivos pintados en distintas tonalidades de rojo (Figura 3b y d y Tabla 2), entre los que se destaca la presencia de manchas y dos positivos de mano. Parte de las pinturas evidencian descamación de la superficie y un importante estado de deterioro atribuible a su exposición a los fogones modernos presentando una potente capa de hollín (Figura 3c) que podría estar ocultando motivos ${ }^{4}$.

\footnotetext{
${ }^{4}$ En colaboración con miembros del Instituto de Investigaciones sobre el Patrimonio Cultural (IIPC-Tarea, Universidad Nacional de San Martín), se está programando llevar a cabo un análisis de Fluorescencia de
}

Al pie del sector con mayor reparo se excavó una cuadrícula de 0,5 por $1 \mathrm{~m}$, alcanzándose una profundidad de $60 \mathrm{~cm}$ de sedimento estéril. Esta ausencia de materiales se explica por la pendiente del terreno que hace suponer la existencia de erosión laminar y arrastre de materiales pendiente abajo. Para chequear esta posibilidad se prospectaron los alrededores del sitio, pero no se encontraron otros materiales aunque si se localizó una estructura de piedra (Solís 2, ver en Tabla 1).

\section{Integrando la evidencia}

Consideraremos ahora los resultados de las excavaciones en conjunto con el resto de las evidencias del valle del Pico procedentes de colecciones privadas, materiales de superficie y el arte rupestre.

\section{Arte rupestre}

Los motivos presentes en los sitios Acevedo 1 y Solís 1 se corresponden con la Tendencia Abstracto Geométrico Compleja (TAGC, Gradin, 1999) o estilo de grecas (Menghin, 1957). A esta evidencia debe sumarse la del sitio Piedra Pintada del Jaramillo (Figura 1), un bloque errático que se encuentra situado a un lado de la actual ruta provincial $\mathrm{N}^{\circ} 44$, en cuya cara Norte se registró un motivo desvaído de color rojo que en la Tabla 2 figura como indeterminado. Así, los sitios con arte rupestre que hemos localizado ${ }^{5}$ en el valle del río Pico se ubican en reparos rocosos altamente visibles, situados a la vera de caminos y compuestos por pocos motivos pintados y con un repertorio limitado. Como puede verse en la Tabla 2, los motivos compartidos entre sitios son pocos: puntiformes, positivos de mano y manchas. Respecto de

Rayos $X$ bidimensional con detección dispersiva de energía en este sector del bloque para determinar si hay motivos de arte rupestre ocultos.

${ }^{5}$ En otros trabajos hemos mencionado los problemas de visibilidad que implican las investigaciones arqueológicas en el bosque (por ejemplo Scheinsohn, 2004) y la ventaja que presentan las prospecciones dirigidas en un ambiente de estas características (Bellelli et al., 2003), por lo que la estrategia que hemos preferido en el Pico es esta última. 


\begin{tabular}{|l|c|c|c|}
\hline \multicolumn{1}{|c|}{ Motivo } & Acevedo 1 & Solis 1 & Piedra Pintada del Jaramillo \\
\hline puntiforme & 1 & 1 & - \\
\hline trazo vertical & 2 & - & - \\
\hline trazo grueso & 2 & - & - \\
\hline trazos paralelos & 10 & - & - \\
\hline tridígito & 3 & - & - \\
\hline zigzag vertical & - & 1 & - \\
\hline trazo rectilineo cerrado & 1 & - & - \\
\hline trazo continuo en forma de flecha & 1 & - & - \\
\hline greca irregular & - & 2 & - \\
\hline peiniforme & 1 & - & - \\
\hline tridigito encerrado en un cuadrado & 1 & - & - \\
\hline puntiforme encerrado en un cuadrado & 1 & - & - \\
\hline trazos paralelos encerrados en un circulo & 1 & - & - \\
\hline negativo de objeto triangular & 1 & - & - \\
\hline círculos concéntricos & 1 & - & - \\
\hline sol concéntrico & 1 & - & - \\
\hline medio sol & 1 & - & - \\
\hline positivo de mano & 1 & 2 & - \\
\hline negativo de mano & 1 & - & 1 \\
\hline mancha & 4 & 5 & - \\
\hline indeterminado & 3 & 11 & - \\
\hline & & & - \\
\hline
\end{tabular}

Tabla 2. Listado de motivos rupestres registrados en los sitios Acevedo 1 y Solís 1.

Table 2. List of rock motifs registered in the Acevedo 1 and Solis 1 sites.

estas últimas, en Acevedo 1 se detectó un nicho natural cubierto por una capa de pintura roja, sobre la que se disponen motivos en otras tonalidades de ese color. Si bien se pudo identificar una mezcla de hematita y yeso en el estrato pictórico, no fue posible determinar si el yeso procede de la pared rocosa o es parte de una preparación del soporte (Marte, 2015).

\section{Restos óseos humanos}

A la evidencia recuperada en Acevedo 1 se le suman las colecciones privadas que fueron relevadas por nuestro equipo. En la Escuela Primaria $N^{\circ} 75$ de Río Pico se localizó un conjunto de diez elementos post craneales (principalmente huesos largos, vértebras y costillas) correspondientes a un individuo adulto que, según se nos informó, fue hallado en un alero ubicado cerca de Solís 1 y llevado a la escuela. Gracias a la información brindada por quién encontró los restos (J. Solís), pudimos ubicar el lugar de hallazgo, el sitio que denominamos Solís Sepultura (Figura 1). Las prospecciones allí realizadas no permitieron identificar materiales arqueológicos en superficie.

Además, localizamos y fechamos un cráneo depositado en el Museo de Ciencias Naturales de la Universidad
Nacional de La Plata procedente del Campamento de Río Pico de la Comisión de Límites del Museo de la Plata que estuvo trabajando en la zona a principios del siglo XX, que fuera recuperado por Carlos Habegger y que figura en el catálogo de Lehmann-Nitsche (1910) con el número 1030, miembro. El mismo fue datado en $823 \pm 29$ AP (AA106705, óseo, calibrado con dos sigmas en 12121284 cal A.D). Para este cráneo se obtuvieron también valores de $\delta 13 \mathrm{C}=-19,4$ y $\delta 15 \mathrm{~N}=11,9$

\section{Artefactos líticos}

Las dispersiones líticas comprenden a los sitios Mayer 1, Acevedo 2 y Delgado 1 (Figura 1 y Tabla 1), cuyos materiales fueron recuperados por los propietarios de los respectivos predios. Mayer 1 se localiza en un claro usado para cultivo. Las piezas se encontraron al arar el campo (Rizzo et al., 2016). Por su parte, Acevedo 2 y Delgado 1 se ubican sobre huellas vehiculares. En ambos casos los artefactos fueron recolectados a medida que el paso de vehículos profundizaba estas huellas y los iba exponiendo.

En todos los conjuntos líticos, predominan los desechos de talla seguidos de los instrumentos, aunque la proporción entre desechos e instrumentos de las colecciones privadas

\begin{tabular}{|l|c|c|c|c|}
\hline Artefactos formatizados & Acevedo 2 & Mayer 2 & Delgado 1 & Acevedo 1 \\
\hline raedera & 3 & 3 & 2 & - \\
\hline raspador & 6 & 11 & 1 & - \\
\hline bifaz & 1 & - & - & 1 \\
\hline punta & 3 & - & 1 & - \\
\hline limace & 1 & - & - & - \\
\hline denticulado & 1 & - & - & - \\
\hline cuchillo & - & - & 1 & - \\
\hline artefacto no diferenciado & 13 & - & - & - \\
\hline punta entre muescas & 3 & - & - & - \\
\hline bola lítica & - & - & 1 & - \\
\hline Total artefactos formatizados & $31(41,9 \%)$ & $14(23,73 \%)$ & $6(28,6 \%)$ & $1(0,44 \%)$ \\
\hline Núcleos & $3(4,05 \%)$ & $1(1,7 \%)$ & $2(9,5 \%)$ & - \\
\hline Desechos de talla & $40(54,05 \%)$ & $44(74,57 \%)$ & $13(61,9 \%)$ & $225(99,56 \%)$ \\
\hline Total & $74(100 \%)$ & $59(100 \%)$ & $21(100 \%)$ & $226(100 \%)$ \\
\hline
\end{tabular}

Tabla 3. Tipos y frecuencias de artefactos líticos de los conjuntos procedentes de colecciones privadas (Acevedo 2, Mayer 2 y Delgado 1) y excavación (Acevedo 1).

Table 3. Types and frequencies of lithic artifacts from private collections (Acevedo 2, Mayer 2 y Delgado 1) and excavation (Acevedo 1). 
es menor que en la muestra procedente de la excavación de Acevedo 1 (Tabla 3). En cuanto a las colecciones privadas, Acevedo 2 es el que presenta mayor diversidad de instrumentos (siendo los artefactos no diferenciados la categoría más representada) y es la única que presenta piezas termoalteradas (tres puntas de proyectil, un núcleo de calcedonia, dos raspadores de sílice y tres desechos de talla).

En cuanto a los tipos de instrumentos, las puntas de proyectil están representadas por tres ejemplares de módulo pequeño en Acevedo 2 (una punta triangular pedunculada de sílice marrón entera y posiblemente reactivada, un fragmento de pedúnculo y un fragmento de punta, ambos de sílice blanco) y por una punta triangular pedunculada de calcedonia marrón en Delgado 1. Cabe destacar la presencia de una bola lítica en Delgado 1, ubicado en Lago $N^{\circ} 3$ (ver Figura 1) donde además relevamos otras dos bolas procedentes de otra colección privada, aunque en este caso no pudimos localizar más precisamente el lugar del hallazgo. En las tres colecciones están presentes las raederas y los raspadores (Tabla 3). En cuanto a las materias primas, sílice y calcedonia dominan en todos los conjuntos. La andesita, si bien está presente en todos los conjuntos, sólo se encuentra en altas frecuencias en Acevedo 1 mientras que la obsidiana sólo está presente en este último sitio (Figura 4).

\section{Estructuras de piedra}

Se identificaron dos estructuras de piedra. Solís 2 (Figura 1 y Tabla 1) se ubica a 60 metros cuesta abajo de Solís 1. Se trata de una depresión circular de 8,20 por 6,6 m, recubierta por rocas disponibles en el entorno inmediato. Las prospecciones realizadas en el interior y alrededores de dicha estructura no arrojaron resultados por lo que para establecer su funcionalidad sería necesario plantear una excavación. Mayer 2 (Figura 1 y Tabla 1) es una estructura oval que mide 6,75 por 3,70 m y está situada en la cima de un pequeño promontorio, aproximadamente a 1,5 km de Mayer 1. Según nos informó la familia, Mayer se trataría de un chenque del que se saquearon restos óseos humanos. No registramos materiales arqueológicos en superficie.

\section{Discusión: la construcción de nicho en el valle del Pico}

A la luz de la TCN, el paisaje puede considerarse como resultado de la interacción entre los organismos y su ambiente, que es heredado e incluye modificaciones y marcas que configuran un ambiente transmitido y construido (Belardi et al., 2016; Muscio, 2009).

En tanto la comunicación es una instancia de la construcción de nicho que, a través de signos, señales o artefactos, apunta a cambiar la conducta de los conspecíficos (Aunger, 2009:37) existen una serie de marcas en el paisaje (sensu Lovis y Whallon, 2016) que lo modifican de manera intencional y son claramente enmarcables en la TCN. Pero también hay instancias no intencionales (Aunger, 2009; Belardi et al., 2016; Lovis y Whallon, 2016) de esas modificaciones donde el ojo entrenado puede leer información. A continuación, discutiremos estas dos instancias en el valle del Pico.

\section{Construcción de nicho intencional: el ambiente construido}

\section{Arte rupestre}

En tanto la transmisión cultural forma parte del nicho humano, el arte rupestre es interpretable en términos de la TCN (Belardi et al., 2016). En esa línea, Caridi y Scheinsohn (2016) sostuvieron que los sitios con arte rupestre constituyen la fosilización de redes de información conformando lo que denominamos Caminos Arqueológicos de Transmisión Cultural (CATC), constituidos por asociaciones estadísticamente significativas, pero tiempo-comprimidas, entre pares de motivos que se dan en los nodos o sitios de esas redes.

En tanto los sitios con arte rupestre del valle del Pico se encuentran cerca de caminos y rutas actuales (que posiblemente hayan sido trazados sobre las tradicionales) y en lugares accesibles y de alta visibilidad, se puede sugerir que habrían funcionado como marcadores de rutas, colaborando con la navegabilidad terrestre y operando como landmarks o hitos de un ambiente

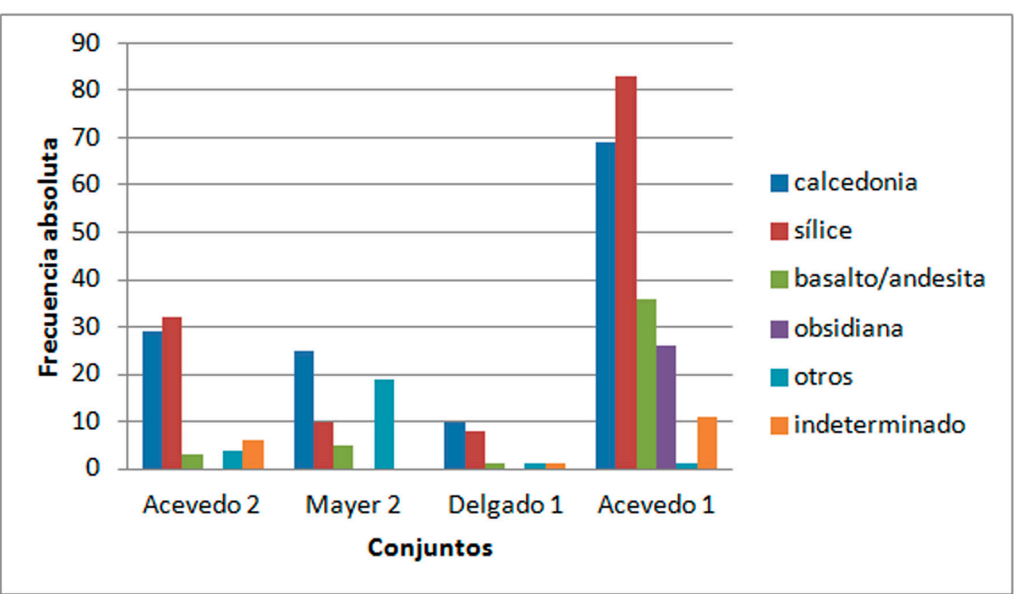

Figura 4. Frecuencias de materias primas registradas en conjuntos líticos de colecciones privadas (sitios Acevedo 1, Mayer 2 y Delgado 1) y excavación (Acevedo 1). Nota: la categoría "otros" incluye xilópalo, cuarcita, riolita, toba silicificada, limolita y feldespato.

Figure 4. Raw materials frequencies of lithic artifacts recovered in private collections (Acevedo 1, Mayer 2 and Delgado 1 sites) and in excavation (Acevedo 1). Note: the category "other" includes xylopal, quartzite, rhyolite, silicified tuff, siltstone and feldspar. 
transmitido. Esta tendencia deberá ser confirmada a futuro mediante nuevas prospecciones para luego poder evaluar el nivel de riesgo (Scheinsohn y Matteucci, 2013) de los corredores en los que se sitúan ya que el pequeño tamaño de muestra actual impide esta consideración.

Por otro lado, el arte rupestre del valle del Pico sólo presenta motivos geométricos (TAGC) pintados, lo cual argumenta respecto de su carácter tardío. Los motivos compartidos entre sitios son pocos y hay pocos motivos por sitio, con espacios libres y sin superposiciones ${ }^{6}$. Acevedo 1 y Solís 1 fueron analizados en conjunto con los cercanos Lago Verde 1 y 2, ubicados ya en Chile (Caridi y Scheinsohn, 2016). Los cuatro sitios están sólo presentes en uno de los seis clusters registrados, constituido por motivos lineales y reticulados (cluster 3 ). Este cluster es solo uno de los que fueron detectados en el sector que denominamos Norte de Patagonia y que incluye las áreas de Pilcaniyeu, Nahuel Huapi, Comarca Andina del Paralelo $42^{\circ}$, Parque Nacional Los Alerces, Traful y Piedra Parada. Durante el Holoceno tardío este sector se habría encontrado en una etapa de ocupación efectiva del espacio (sensu Borrero, 1994-1995), mientras que sostuvimos que el valle del Pico estaría en vías de exploración (Scheinsohn et al., en prensa). Todo lo antedicho permite plantear como hipótesis que en este valle la construcción de nicho estaría en sus inicios.

\section{Registro funerario y estructuras de piedra}

Otra forma de señalamiento intencional es el registro funerario que puede dejar diferentes tipos de señales en función de su visibilidad. En Acevedo 1, el alto grado de mezcla y desarticulación en que fueron hallados los restos sugiere la ausencia de estructuras funerarias que los contuvieran y/o dieran algún tipo de protección (Zangrando et al., 2004). A esto se suma la falta de materiales que puedan atribuirse específicamente a acompañamientos funerarios (elementos expresamente dispuestos con los individuos como parte del ritual mortuorio, O'Shea, 1984). Estas características lo definen como un entierro de tipo expeditivo (Walthall, 1999) que se asocia a grupos pequeños de cazadores-recolectores altamente móviles (Barrientos, 2002; Walthall, 1999), lo cual es compatible con un momento de exploración (Rizzo, 2018), apoyando la idea un nicho de reciente ocupación. Ahora bien, además de los entierros en alero (Acevedo 1 y Solís Sepultura) hay información de al menos un chenque saqueado (Mayer 2), lo que podría leerse en términos de una marcación intencional del paisaje. A este señalamiento debe agregarse la presencia de estructuras de piedra, como la de Solís 2, cuya función no pudo determinarse y de sendas o caminos como el utilizado en tiempos históricos con destino hacia Aldea Las Pampas.

\section{Construcción de nicho no intencional}

\footnotetext{
${ }^{6}$ Con la excepción de la mancha que ocupa el nicho rocoso de Acevedo 1 que, como se dijo, no es claro si se trata de una preparación de soporte o es un teñido natural de la roca.
}

Entre las marcaciones del espacio no intencionales (Lovis y Whallon, 2016) puede registrarse el uso acumulativo de lugares para su uso residencial con la consiguiente alteración no intencional de los suelos (algo que se argumentó para ciertos sitios de Cholila, ver Scheinsohn, 2004) y cambios en los patrones y composición de la vegetación (Lovis y Whallon, 2016). En este sentido la propuesta de Belmar et al. (2017) sobre la posibilidad de encontrar plantas comestibles en torno a sitios arqueológicos, como subproducto no intencional de su explotación por parte de cazadores-recolectores, es un aspecto interesante a explorar a futuro en los bosques de la Patagonia. Si bien no podríamos esperar una situación similar a la de los trópicos (como la que se daría entre los Nukak, ver Politis, 2007, en el cual se refiere mayoritariamente al caso de las palmeras), sería esperable encontrar malezas comestibles (como las que mencionan Rapoport et al., 2009) o aquellas utilizadas para realizar artefactos, en los alrededores de los sitios arqueológicos. Esto llevaría a una retroalimentación positiva de más ocupaciones que son atraídas al mismo lugar y la ampliación o renovación de los "huertos" no intencionales. También podría esperarse un equipamiento de sitio, especialmente de aquellos artefactos asociados al procesamiento de vegetales. Pero este no ha sido el caso en el Pico, donde no se registraron. EEsta ausencia puede explicarse como un mero problema de visibilidad o a que los recursos vegetales aprovechados en el bosque no requirieran de tecnologías específicas como molinos o contenedores de cerámica. Sólo un programa de investigación arqueobotánica intensivo y el incremento del muestreo de sitios en el bosque permitirán resolver estas cuestiones.

Respecto de la disponibilidad de agua y cómo su abundancia o escasez habría planteado distintas estrategias en la construcción de nicho, sólo podemos apelar a la evidencia paleoambiental publicada, que no muestra eventos marcados de aridez aunque sí existen evidencias de variaciones interanuales en el último tramo del Holoceno. Si bien en el Cisnes la correlación cronológica entre los eventos de incendios y de ocupaciones humanas lleva a sugerir la incidencia del factor humano en el incremento de incendios detectados (Méndez et al., 2016), no es posible evaluar esta situación en el Pico en vista de los pocos fechados con que contamos hasta el momento. Así, habría que incrementar la muestra de fechados y obtener información paleoambiental a escala local. De todos modos, en un área con alta frecuencia de incendios, sería esperable encontrar un porcentaje importante del registro arqueológico termoalterado. En ese sentido, si bien es interesante la presencia de artefactos quemados en Acevedo 2, la falta de contexto hace difícil determinar si se trata de una termoalteración posterior a su depositación (por la ocurrencia de un incendio forestal como se argumentó en Carballido y Bellelli, 2020) o de tratamiento térmico de la materia prima. 
Dentro de las marcaciones no intencionales deberíamos considerar las sendas de animales que pueden haber servido a los cazadores-recolectores para circular en el bosque y que son usadas en la actualidad para el tránsito a caballo o a pie. También, las dispersiones líticas superficiales aunque en el ambiente boscoso del Pico, donde predominan los procesos de sedimentación y existe una importante cobertura vegetal, lo esperable es que su visibilidad sea acotada temporalmente.

Además, debemos hacer mención al registro faunístico en tanto, mediante la acumulación de huesos, permite definir bonescapes, esto es "landscapes in whose construction faunal remains, which are loaded with different layers of meanings that are significant to the perception and conceptualization of the land, had a central role" (Politis, 2016:153). Politis argumenta que, si bien no recibieron la misma atención que el arte rupestre $u$ otro tipo de señalamiento, los huesos de los animales juegan un papel en la creación y percepción del paisaje y son instrumentales en construir y señalar el territorio (Politis, 2016:153). Sin embargo, a este caso debe aplicarse lo mismo que se sostuvo para las dispersiones líticas: en tanto la sedimentación es alta y la vegetación frondosa, su utilidad debe haber estado limitada a momentos penecontemporáneos a su depositación.

Ya fuera del terreno de las marcaciones, el estudio de ese registro arqueofaunístico nos permitió evaluar la fauna presente y aquella que fue seleccionada para caza y/o consumo, aportando a la construcción de nicho de los cazadores-recolectores a través de consecuencias no intencionales. A este respecto, en el único sitio en donde existe registro faunístico (Acevedo 1), el alto nivel de fragmentación y la mala preservación limitaron la posibilidad de construir los modos de aprovechamiento de la fauna. La identificación de huemul, nos permite sostener que esa presa estuvo disponible aunque no se pudo corroborar que haya sido aprovechada ya que no presentaba huellas de procesamiento. Tampoco se encontraron huellas en los otros restos identificables. No obstante, los resultados obtenidos de $\delta$ C13 y $\delta$ N15 en las muestras humanas de Acevedo 1 y del campamento Río Pico, indican altos valores del $\delta$ N15 que, según el modelo de Fernández y Tessone (2014), llevan a pensar en una dieta relacionada con recursos de la estepa, es decir, con el guanaco.

En cuanto a las técnicas de caza, las puntas de proyectil líticas de módulo pequeño recuperadas en las colecciones son compatibles con el uso de arco y flecha. También hay que destacar la presencia de bolas líticas en los alrededores de Lago $\mathrm{N}^{\circ} 3$. Si bien se supone que son usadas en ambientes abiertos (Saletta y Sacchi, 2019), su presencia en el bosque es compatible con el modelo propuesto por Fernández y Carballido (2015) para la caza del huemul y el pudú.
Finalmente, las consideraciones que hemos hecho respecto del estrés patogénico que impone el bosque para los humanos, en tanto es clave para definir la distribución de densidades poblacionales y diversas características culturales humanas (Fincher et al., 2008), nos ha llevado a plantear trabajos específicos a este respecto en el marco de nuestro proyecto de investigación. El estudio bioarqueológico y paleopatológico de restos óseos humanos de diversos sectores de Norpatagonia, entre ellos los del valle del Pico, forman parte del proyecto de tesis doctoral en curso de la Lic. Denise Evans, integrante de nuestro equipo. Como parte de esta evaluación paleopatológica también se plantea trabajar a nivel molecular, mediante paleoproteómica, para identificar proteínas y su asociación con inflamación crónica sistémica o patógenos en muestras óseas humanas y faunísticas, como para reconocer posibles zoonosis (como el caso del Hantavirus).

\section{Conclusiones y agenda de trabajo}

Si bien parte de las evidencias se ajustan a las expectativas planteadas, otras necesitan mayor profundización. Consideramos que la ocupación humana de los bosques patagónicos puede ser caracterizada, como argumentó Lovis (2016) para el caso de del interior del Labrador (Canadá), a partir del intento de mantener una red en un "big rough space with few people". Esta situación ambiental y demográfica constriñó la construcción del nicho cazador-recolector. Una de las expectativas confirmadas es que, durante el Holoceno tardío, el valle del río Pico integró los circuitos de movilidad exploratorios realizados por poblaciones asentadas en lugares ya colonizados/ocupados efectivamente desde momentos más tempranos, posiblemente situados en la estepa. Así, el bosque del Pico fue habitado con posterioridad al establecimiento de las condiciones ambientales actuales. Otra expectativa confirmada es que la construcción de nicho en el bosque del valle del Pico se encontraría en un momento inicial. No obstante, existen distintos aspectos, detallados en este trabajo, que necesitan profundizarse.

Por un lado, es necesario ampliar las excavaciones en Acevedo 1, a fin de determinar si hubo un único evento de entierro de restos humanos o varios. Estas ampliaciones también servirán para determinar si la escasez de evidencias de actividades domésticas manifestada hasta el momento se debe a la limitada superficie excavada. También es necesario realizar nuevas prospecciones a fin de incrementar la muestra de sitios excavables, que permitan obtener más material para fechar y registrar más sitios con arte rupestre. Además, nos proponemos desarrollar un programa arqueobótanico que incluya la extracción sistemática de muestras por flotación durante las futuras excavaciones y el estudio de la flora cercana a los sitios detectados. Por otro lado, los estudios bioarqueológicos y paleopatológicos, ya están en curso y pronto producirán resultados. 
Finalmente es necesario el desarrollo de un programa de tafonomía regional en el Pico que incluya tanto el registro óseo (ya en curso en las cercanías de Acevedo1) como lítico. Este último caso aportaría a resolver si el patrón distribucional lítico detectado obedece a problemas de visibilidad o realmente refleja un patrón de ocupación. Poder cumplir con esta agenda nos permitirá incluir el bosque del valle del Pico en la discusión general sobre la construcción de nicho en los bosques patagónicos.

Buenos Aires, 17 de junio de 2020

\section{Agradecimientos}

Queremos agradecer a Pablo Fernández, Mariana Carballido Calatayud y Pablo Tchilinguirián por su colaboración en el análisis de los restos arqueofaunísticos, líticos y geomorfológicos, respectivamente. A Cristina Bellelli y Carolina Belmar por facilitarnos bibliografía. A Denise Evans por sus aportes respecto de la presencia de patógenos en las muestras patagónicas. Agradecemos también a los pobladores y autoridades de Río Pico, en especial a la Familia Acevedo y a la familia Mayer. Este trabajo fue financiado por el proyecto PICT 2016 N $^{\circ} 0901$ dirigido por la Dra. Vivian Scheinsohn y por becas postdoctorales y doctorales de CONICET.

Agradecemos también a los evaluadores anónimos, por las sugerencias que permitieron mejorar este trabajo.

\section{Bibliografía}

AA. VV. (2020). INTA. Sistema de Información Geográfica. Tehuelches-Chubut. Cartilla 7-7, https://inta.gob.ar/sites/ default/files/gis_tehuelches.pdf. (Acceso: 14 de mayo, 2020).

Andrade, A. y Fernández, P. M. (2017). Rodent consumption by hunter-gatherers in North Patagonian Andean forests (Argentina): insights from the small vertebrate taphonomic analysis of two Late Holocene archaeological sites. Journal of Archaeological Science: Reports, 11, 390-399.

Arrigoni, G. (2002). Estudio de un macrovestigio vegetal rescatado en la matriz arqueológica del Alero del Sendero de Interpretación (Parque Nacional Los Alerces, Prov. de Chubut). En C. Pérez de Micou (Comp.), Plantas y cazadores en Patagonia (pp.105-113). Buenos Aires: Facultad de Filosofía y Letras, Universidad de Buenos Aires.

Arrigoni, G. y Fernández, P. M. (2004). Los restos óseos del Alero Sendero de Interpretación (PN Los Alerces, provincia de Chubut): integridad, resolución y aprovechamiento de los recursos faunísticos del bosque. En M. T. Civalero, P. M. Fernández y A. G. Guráieb (Comp.), Contra Viento y Marea. Arqueología de Patagonia (pp. 403-415). Buenos
Aires: Instituto Nacional de Antropología y Pensamiento Latinoamericano, Sociedad Argentina de Antropología.

Aunger, R. (2009). Human communication as niche construction. En Shennan S. J. (Ed.), Pattern and Process in Cultural Evolution (pp. 33-43), Berkeley: University of California Press.

Barrientos, G. (2002). The Archaeological Analysis of Death-Related Behaviors from an Evolutionary Perspective: Exploring The Bioarchaeological Record of Early American Hunter-Gatherer. En J. L. Lanata y G. Martínez (Eds.), Perspectivas Integradoras entre Arqueología y Evolución. Teoría, Método y Casos de Aplicación (pp. 221-254). Olavarría: INCUAPA.

Belardi, J. B., Barberena, R., Goñi, R. y Re, A. (2016). The Development of a Legacy: Evolution, Biogeography, and Archaeological Landscapes. En M. Cardillo y H. Muscio (Eds.), Darwin's Legacy: The Status of Evolutionary Archaeology in Argentina (pp. 83-94). South American Archaeology Series 24. Oxford: Archaeopress.

Bellelli, C., Scheinsohn, V. Fernández, P. M., Podestá, M. y Carballido, M. (2000). Arqueología de la Comarca Andina del Paralelo $42^{\circ}$. Localidad de Cholila. Primeros Resultados. En J. B. Belardi, F. Carballo Marina y S. Espinosa (Eds.), Desde el País de los Gigantes. Perspectivas arqueológicas en Patagonia (pp. 587-602, Tomo II). Río Gallegos: Universidad Nacional de la Patagonia Austral.

Bellelli, C., Carballido, M.,Fernández, P., y Scheinsohn, V. (2003). El pasado entre las hojas. Nueva información arqueológica del noroeste de la provincia de Chubut, Argentina. Revista Werken 4, 25-42.

Bellelli, C., Scheinsohn, V. y Podestá, M. M. (2008). Arqueología de pasos cordilleranos: un caso de estudio en Patagonia norte durante el Holoceno tardío. Boletín del Museo Chileno de Arte Precolombino, 13(2), 37-55.

Belmar, C., Méndez, C. y Reyes, O. (2017). Huntergatherer plant resource use during the Holocene in central western Patagonia (Aisén, Chile, South America). Vegetation, History and Archaeobotany, 26(6), 607-625.

Binford, L. (2001). Constructing Frames of Reference. An Analytical Method for Archaeological Theory Building. Using Hunter-Gatherer and Environmental Data Sets. California: University of California Press.

Borrero, L. (1994-1995). Arqueología de la Patagonia. Palimpsesto, 4, 9-55.

Borrero, L., Nuevo Delaunay, A. y Méndez, C. (2019). Ethnographical and historical accounts for understanding the exploration of new lands: The case of Central Western Patagonia, Southernmost South America. Journal of 
Anthropological Archaeology, 54, 1-16.

Boyd, R. y Richerson, P. J. (1985).Culture and the evolutionary process. Chicago: University of Chicago Press.

Braicovich, R. (2007). Observando la Relación de los Pueblos del Nahuel Huapi con su Paisaje Acuático a partir del Estudio de Canoas Monóxilas. En Actas del $6^{\circ}$ Congreso Chileno de Antropología (pp. 1897- 1905, Tomo II). Valdivia: Colegio de Antropología de Chile.

Carabias, D. (2018). Canoas monóxilas etnográficas de los nómadas canoeros de la Patagonia Occidental y Tierra del Fuego del Museo de Historia Natural de Valparaíso. Colecciones Digitales, Subdirección de Investigación, Servicio Nacional del Patrimonio Cultural, 1-25.

Carabias, D., Lira, N. y Adán, L. (2010). Reflexiones en torno al uso de embarcaciones monóxilas en ambientes boscosos lacustres precordilleranos andinos, zona CentroSur de Chile. Magallania, 38(1), 87-108.

Carballido Calatayud, M. y Bellelli, C. (2020). Historias de agua y fuego. Modificaciones del material lítico en sitios del bosque Norpatagónico. Revista del Museo de Antropología, 13(1), 347-354.

Caridi, I. y Scheinsohn, V. (2016). Mind the Network: Rock Art, Cultural Transmission, and Mutual Information. En L. Mendoza Straffon (Ed.), Cultural Phylogenetics Concepts and Applications in Archaeology (pp.131-170, Volumen 4.). Switzerland: Springer International Publishing.

Caruso Fermé, L. (2013). Experimentation and Combustion Properties of Patagonian Andean Forest. Contribution to the Archaeobotanical Studies of Archaeological Sites. Magallania, 41(2), 145-158.

Cashdan, E. (2014). Biogeography of Human Infectious Diseases: A Global Historical Analysis. PLOS ONE, 9(10), e106752.

Ciampagna, M. L. y Capparelli, A. (2012). Historia del uso de las plantas por parte de las poblaciones que habitaron la Patagonia continental argentina. CazadoresRecolectores del Cono Sur, 6, 45-75.

De Porras, M. E., Maldonado, A., Abarzúa, A. M., Cárdenas, M., Francois, J. P., Martel-Cea, A. (2012). Postglacial vegetation, fire and climate dynamics at Central Chilean Patagonia (Lake Shaman, 44 S), Chile. Quaternary Science Review, 50, 71-85.

Fernández, J. (1997). Canoas arqueológicas de un palo (huampus) recuperadas en los lagos andinos del Noroeste Patagónico. Anuario de la Universidad Internacional SEK, 3, 49-63.
Fernández, M. G. (2018). De huemules y guanacos: Análisis zooarqueológico del sitio Acevedo 1 en el ecotono bosque-estepa del centro-oeste del Chubut. Trabajo presentado en XI Jornadas de Jóvenes Investigadores en Ciencias Antropológicas. Buenos Aires, Argentina.

Fernández, M. G. (en prensa). Zooarqueología del sitio Acevedo 1 (ecotono bosque estepa del centro-oeste de Chubut). Revista del Museo de Antropología.

Fernández, P. M. (2010). Cazadores y presas: 3500 años de interacción entre seres humanos y animales en el Noroeste de Chubut. Buenos Aires: Fundación de Historia Natural Félix de Azara.

Fernández, P. M. y Arrigoni, G. (2016). Aportes para la comprensión de la subsistencia en el bosque del noroeste de Chubut. Nuevos datos del sitio Alero del Shamán (Parque Nacional Los Alerces, Argentina). En M. Saleme, F. Santiago, A. Tívoli, M. Vázquez y A. F. Zangrando (Comp.), Actas del IV Congreso Nacional de Zooarqueología Argentina (p. 99). Ushuaia: Universidad Nacional de Tierra del Fuego.

Fernández, P. M., y Carballido Calatayud, M. (2015). Armas y presas. Técnicas de caza en el interior del bosque patagónico. Relaciones de la Sociedad Argentina de Antropología, 40(1), 279-301.

Fernández, P. M. y Tessone, A. (2014). Modos de ocupación del bosque patagónico de la vertiente oriental de los Andes. Aportes desde la ecología isotópica. Revista Chilena de Antropología, 30(2), 83-89.

Fernández, P. M. y Fernández, M. G. (2020). Interacciones entre los seres humanos y los carnívoros en el bosque de Patagonia centro-septentrional a lo largo del Holoceno. Cuadernos del Instituto Nacional de Antropología y Pensamiento Latinoamericano. Series Especiales 7 (2): 110-116.

Fernández, P. M. y Rizzo, F. (2016). Modalidades de uso del bosque de Patagonia y prácticas mortuorias desde la perspectiva del sitio Población Anticura (Suroeste de Río Negro). En Actas del XIX Congreso Nacional de Arqueología Argentina. Serie Monográfica y Didáctica (pp. 712-717, Volumen 54). Tucumán: Facultad de Ciencias Naturales e Instituto Miguel Lillo, Universidad Nacional de Tucumán.

Fernández, P. M., Carballido Calatayud, M., Bellelli, C. y Podestá, M. (2013). Tiempo de cazadores. Cronología de las ocupaciones humanas en el valle del río Manso inferior (Río Negro). En: A. F. Zangrando, R. Barberena, A. Gil, G. Neme, M. Giardina, L. Luna, C. Otaola, S. Paulides, L. Salgán y A. Tivoli (Comp.), Tendencias teóricosmetodológicas y casos de estudio en la arqueología de Patagonia (pp. 167-175). Buenos Aires: Museo de Historia 
Natural San Rafael de Mendoza, Sociedad Argentina de Antropología, Instituto Nacional de Antropología y Pensamiento Latinoamericano.

Fernández, P. M., Cruz, I., Belardi, J. B., De Nigris, M. y Muñoz, S. (2016). La explotación del huemul (Hippocamelus bisulcus, Molina 1782) en la Patagonia a lo largo del Holoceno. Magallania, 44(1), 187-209.

Fincher, C. L., Thornhill, R., Murray, D. R. y Schaller, M. (2008). Pathogen prevalence predicts human cross-cultural variability in individualism/collectivism. Proceedings of the Royal Society B: Biological Sciences, 275(1640), 1279-1285.

Gnecco C. (2000). Ocupación Temprana de Bosques Tropicales de Montaña. Popayán: Editorial Univ. Cauca.

Groß, D., Piezonka, H., Corradini, E., Schmölcke, U., Zanon, M., Dörfler, W., Dreibrodt, S., Feeser, I., Krüger, S.,Lübke, H., Panning, D. y Wilken, D. (2019). Adaptations and transformations of hunter gatherers in forest environments: New archaeological and anthropological insights. The Holocene 29(10), 1531-1544.

Golledge. R. (2003). Human wayfinding and cognitive maps. En M. Rockman y J. Steele (Eds.), Colonization of unfamiliar landscapes. The archaeology of adaptation (pp. 25-43). Londres: Routledge.

Gradin, C. (1978). Algunos aspectos del análisis de las manifestaciones rupestres. Revista del Museo Provincial, 1, 120-133.

Gradin, C. (1999). Sobre las tendencias del arte rupestre de Patagonia argentina. En M. Tamagnini (Comp.), Segundas Jornadas de Investigadores en Arqueología y Etnohistoria del Centro-Oeste del País (pp. 85-99). Río Cuarto: Universidad de Río Cuarto.

Iglesias, V., Markgraf, V. y Whitlock, C. (2016). 17,000 years of vegetation, fire and climate change in the eastern foothills of the Andes (lat. 44 S). Palaeogeography, Palaeoclimatology, Palaeoecology, 457, 195-208.

Kendal, J., Tehrani, J. J. y Odling-Smee, J. (2011). Human niche construction in interdisciplinay focus. Philosophical Transaction of the Royal Society B, 366, 785-792.

Ladio A., Lozada, M. y Weigandt, M. (2007).Comparison of traditional wild plant knowledge between aboriginal communities inhabiting arid and forest environments in Patagonia, Argentina. Journal of Arid Environments, 69, 695-715.

Laland, K., Odling-Smee, J. y Feldman, M. (2000).Niche construction, biological evolution, and cultural change. Behavioral and Brain Sciences, 23, 131-175.
Lehmann-Nitsche, R. (1910). Catálogo de la Sección Antropología del Museo de La Plata. Buenos Aires: Imprenta Coni Hnos.

Leonardt, S., Scheinsohn, V., Rizzo, F., Tchilinguirian, P. (2016). The memory of the landscape: Surface archaeological distributions in the Genoa Valley (Argentinean Patagonia). Quaternary International, 422(11), 5-18.

Lewontin, R. C. (1982). Organism and environment. En E. C. Plotkin (Ed.), Learning, Development and Culture (pp. 151-170). Nueva York: Wiley.

Lovis, W. y Whallon, R. (2016). The Creation of Landscape Meaning by Mobile Hunter-Gatherers. En W. Lovis, y R. Whallon (Eds.), Marking the Land Hunter-Gatherer Creation of Meaning in their Environment (pp. 1-11). Londres: Routledge.

Lovis, W. (2016). Network Maintenance in Big Rough Spaces with Few People: The Labrador Innu-Naskapi or Montagnais. En W. Lovis, y R.Whallon (Eds.), Marking the Land Hunter-Gatherer Creation of Meaning in their Environment (pp. 116-130). Londres: Routledge

Low, B. S. (1990). Marriage systems and pathogen stress in human societies. American Zoologyst, 30, 325-339.

Marconetto, M. B. (2002). Análisis de los vestigios de combustión de los sitios Alero Don Santiago y Campo Moncada. En C. Pérez de Micou (Comp.), Plantas y cazadores en Patagonia (pp. 33-54). Buenos Aires: Facultad de Filosofía y Letras, Universidad de Buenos Aires.

Marte, F. (2015). Informe sobre fragmento de roca con pintura del sitio Acevedo 1. Manuscrito inédito.

Martínez, G. y Mackie, Q. 2003-2004. Late Holocene human occupation of the Quequén Grande river valley bottom: settlement systems and an example of a built environment in the Argentine pampas. Before Farming, 1, 178-202.

Matteucci, S. D., Scheinsohn, V., Rizzo, F. y Leonardt, S. (2011). Rutas de comunicación trasandina de los cazadores- recolectores en el Centro - Oeste de Chubut. Geosig, 3, 183-200.

Méndez, C., Reyes, O., Nuevo Delaunay, A., Velásquez, H., Trejo, V., Hormazábal, N., Solari, M. y Stern, C. R. (2016). Las Quemas rockshelter: understanding human occupations of Andean forests of central Patagonia (Aisén, Chile), southern south America. Latin American Antiquity, 27(2), 207-226.

Méndez, C., Velásquez, H., Reyes, O. y Trejo, V. (2006). 
Tras los moradores del bosque. Análisis de los conjuntos arqueológicos de Alero El Toro (Valle del río Cisnes, Región de Aisén). Werken, 8, 101-115.

Menghin, O. F. A. (1957). Estilos de arte rupestre de Patagonia. Acta Praehistorica I: 57-87. Buenos Aires: Centro de Estudios Prehistóricos.

Moya, F. y Cordero, R. (2019). Hacia una reevaluación del arte rupestre de Patagonia Central de Chile. En D. Rolandi (Ed.), CONAR III Tercer Congreso Nacional de Arte Rupestre (p. 69). Buenos Aires: Asociación Amigos del Instituto de Antropología.

Muscio, H. J. (2009). Nicho y estrategia predominante. Dos conceptos necesarios en Arqueología Evolutiva. En M. C. Barboza, J. E. Avila, C. Piccoli y J. Conaglia Fernández (Eds.), 150 años después... La vigencia de la Teoría Evolucionista de Charles Darwin (pp.83-105). Rosario: Universidad Nacional de Rosario.

Musters, G. ([1871] 2007). Vida entre los Patagones. Buenos Aires: Continente.

Nacuzzi L. R. y Pérez de Micou, C. (1983 - 1985). Los recursos vegetales de los cazadores de la cuenca del río Chubut. Cuadernos del Instituto Nacional de Antropología y Pensamiento Latinoamericano, 10, 407-423.

Odling-Smee, F. J. (1988). Niche constructing phenotypes. En H. C. Plotkin (Ed.), The role of behavior in evolution (pp. 73-132).Cambridge: MIT Press.

Odling-Smee, F. J., Laland, K. N. y Feldman, M. W. (2003). Niche construction: the neglected process in evolution. Princeton: Princeton University Press.

O'Shea, J. (1984). Mortuary Variability. An archaeological investigation. Florida: Academic Press.

Pérez de Micou, C. (1991). Fuego, fogones y señales. Una aproximación a las estructuras de combustión en el Chubut medio. Arqueología, 1, 125-150.

Pérez de Micou, C. (2002). Del bosque a la estepa. La caña coligüe, visibilidad arqueológica de una materia prima vegetal. En C. Pérez de Micou (Comp.), Plantas y cazadores en Patagonia (pp. 65-87). Buenos Aires: Facultad de Filosofía y Letras, Universidad de Buenos Aires.

Politis G. (2007). Nukak: ethnoarchaeology of an Amazonian people. Walnut Creek: Left Coast Press.

Politis G. (2016). Bonescapes: Engaging People and Land with Animal Bones among South American Tropical Foragers. En W. Lovis, y R. Whallon (Eds.), Marking the
Land Hunter-Gatherer Creation of Meaning in their Environment, (pp. 152-179). Londres: Routledge.

Polop, F., Levis S., Pini N., Enria D., Polop J., Provensal, M.C. (2018). Factors associated with hantavirus infection in a wild host rodent from Cholila, Chubut Province, Argentina. Mammalian Biology, 88, 107-113.

Rapoport, E. y A. Ladio (1999). Los bosques andinopatagónicos como fuentes de alimento. Bosque, 20(2), 55-64.

Rapoport, E. Marzocca, A. y B. Drausal (2009). Malezas Comestibles del Cono Sur y otras partes del planeta. Buenos Aires: Instituto Nacional de Tecnología Agropecuaria.

Reyes, O. (2003). Evaluación de los sitios arqueológicos descubiertos en los sectores de Planicie y Semillero, curso superior del valle del Lago Verde, cuenca hidrográfica del río Palena. Región de Aisén. Piedras Patagónicas. www. piedraspatagonicas.cl (Acceso: 10 de mayo de 2011).

Rivero, D. y Medina, M. (2016). Human Holocene Colonization, Diet Breadth and Niche Construction during Sierras of Córdoba (Argentina). En H. Muscio, y M. Cardillo (Eds.), Darwin's Legacy: The State of Evolutionary Archaeology in Argentina, (pp. 67-81) South American Archaeology Series No 24. Oxford: Archaeopress.

Rizzo, F. (2017). Sitio Acevedo 1: restos óseos humanos en el bosque del noroeste de Patagonia (localidad de Río Pico, provincia del Chubut). Intersecciones en Antropología, 18(1), 103-112.

Rizzo, F. (2018). Poblamiento holocénico y registro funerario en el noroeste y centro-oeste de la Patagonia. (Tesis de doctorado inédita), Universidad de Buenos Aires, Argentina.

Rizzo, F. y Fernández, M. G. (2020). Historias tafonómicas comparadas de restos óseos humanos y faunísticos del sitio Acevedo 1, valle del río Pico (Chubut, Argentina). Comechingonia, 24 (2), 55-75.

Rizzo, F., Scheinsohn, V. y Leonardt, S. (2016). Registro arqueológico a cielo abierto en las cuencas de los ríos Genoa y Pico. En F. Mena (Ed.), Arqueología de la Patagonia: de mar a mar (pp. 277-286). Coyhaique: CIEP/Ñire Negro.

Rowley-Conwy, P. y Layton, R. (2011). Foraging and farming as niche construction: stable and unstable adaptations. Philosophical transactions of the Royal Society of London. Series B, Biological Sciences, 366(1566), 849-862.

Saletta, M. J. y Sacchi, M. (2019) ¿Ausencias o abandonos? 
Las puntas de proyectil en sitios post contacto de Patagonia meridional (siglos XVI al XX). Revista de Estudios Sociales, 67, 101-114.

Scheinsohn, V. (2004). "En el país de los ciegos el tuerto es rey": visibilidad arqueológica y paisaje en la localidad de Cholila. En M. T. Civalero, P. Fernández y A. G. Guraieb (Eds.), Contra Viento y Marea. Arqueología de Patagonia (pp. 581-590). Buenos Aires: Instituto Nacional de Antropología y Pensamiento Latinoamericano- Sociedad Argentina de Antropología.

Scheinsohn, V. (2011). Rock art information among hunter-gatherers in northwest Patagonia: An assessment of broad-scale and territorial models. En R. Whallon, W. Lovis y R. Hitchcock (Eds.), Information And Its Role in Hunter-Gatherer Bands (pp. 85-115). Los Angeles: Cotson Institute for Archaeology.

Scheinsohn, V. y Matteucci, S. (2004). Spaces and species: archaeology, landscape ecology and spatial models in northern Patagonia. Before Farming, 1, artículo 2.

Scheinsohn, V. y Matteucci, S. (2013). A regional model of archaeological distributions for northwestern Andean Patagonia (Argentina.). En M. J. Figuerero Torres y A. D. Izeta (Eds.), El uso de Sistemas de Información Geográfica (SIG) en arqueología sudamericana, South American Archaeology Series N¹8 (pp. 62-72). Oxford: BAR International Series.

Scheinsohn V., Fernández, P. M., Garrone, F., Catelli, L., Longaray, M., Romero, M., Salado, M., Fernández, M. G., Tchilinguirián, P. y Vullo, C. (2016). Identificación taxonómica mediante Citocromo b. Su aplicación a un caso arqueológico patagónico. Intersecciones en Antropología, 17, 281-289.
Scheinsohn, V., Rizzo, F. y Leonardt, S. (en prensa). Macroescalas, poblamiento y registro arqueológico en el Noroeste y Centro Oeste de Patagonia. Chungara.

Smith, R. C. (1998). El uso del bosque nativo por comunidades indígenas: beneficios de reservas extractivas abiertas al turismo. En III Congreso Chileno de Antropología (pp. 1005-1014). Temuco: Colegio de Antropólogos de Chile.

Stuiver, M. y Reimer, P. J. (1993). Calib Radiocarbon Calibration Program. Radiocarbon, 35, 215-230.

Toledo, C. y Kutschker, A. (2012). Plantas Medicinales en el Parque Nacional Los Alerces, Chubut, Patagonia Argentina. Boletín de la Sociedad Argentina de Botánica, 47(3-4), 461-470.

Walthall, J. (1999). Mortuary behavior and early Holocene land use in the North American midcontinent. North American Archaeologist, 20(1), 1-30.

Weissbrod, L., Marshall, F. B., Valla, F. R. y Cucchi, T. (2017). Origins of house mice in ecological niches created by settled hunter-gatherers in the Levant 15,000 y ago. Proceedings of the National Academy of Sciences, 114(16), 4099-4104.

Zangrando, F., M. Del Papa, C. Negro y Arregui, M. J. (2004). Estudios tafonómicos en entierros humanos de la cuenca del lago Salitroso, Santa Cruz. En: M. T. Civalero, P. Fernández, y A. G. Guraieb (Eds.), Contra Viento y Marea. Arqueología de Patagonia (pp. 375386). Buenos Aires: Instituto Nacional de Antropología y Pensamiento Latinoamericano - Sociedad Argentina de Antropología. 